\title{
A Study to Determine the Accuracy of Various Clinical Techniques of Ridge Mapping before Implant Fixture Placement
}

\author{
S Sriram Balaji ${ }^{1}$, Vinaya Bhat ${ }^{2}$
}

\begin{abstract}
Aim: The most important parameter to assess prior to implant fixture placement is the available bone width. Radiographic techniques have been found to be inadequate in providing this valuable information, unlike clinical techniques. The purpose of the present study was to determine the accuracy of various clinical techniques of ridge mapping before implant fixture placement.

Materials and methods: Ten patients with at least two missing teeth adjacent to each other were selected for the study. Direct and indirect techniques of ridge mapping were carried out to assess the available bone width.

Results: The data obtained were statistically analyzed using ANOVA and Tukey's Post Hoc analysis. The results indicate that there is no significant difference between direct and indirect technique of ridge mapping.

Conclusion: Either direct or indirect technique of ridge mapping can be used to assess the width of available bone before implant fixture placement.

Clinical significance: Clinical techniques of ridge mapping are handy and can be carried out chairside with ease and less cost and no radiation exposure. Indirect techniques of ridge mapping provide adequate and reliable data regarding bone width just like direct technique. In the absence of a bone mapping caliper, this technique can be used as a diagnostic procedure before implant placement. And during the indirect technique, any material can be utilized with equal efficacy for the fabrication of the guides.
\end{abstract}

Keywords: Bone calliper, Bone width measurement, Dental implants, Ridge mapping.

The Journal of Contemporary Dental Practice (2019): 10.5005/jp-journals-10024-2546

\section{INTRODUCTION}

$\mathrm{P}$ osthetically driven implant dentistry provides the best esthetic and functional outcome for the patient. To achieve the desired outcome, a detailed preoperative assessment and meticulous treatment planning is mandatory. The most important diagnostic factor prior to implant placement is to assess the width and height of the existing alveolar bone. ${ }^{1,2}$ Errors in the preoperative assessment of existing alveolar bone may lead to a critical situation once the flap is reflected. It may affect a change in the treatment plan on the operating table or may also lead to nonplacement of implants. To avoid such an embarrassment, various clinical and radiographic techniques are available to assess the level of alveolar bone before implant placement. Commonly used radiographic techniques are useful to find out only the height of alveolar bone and presence of anatomical structures. The cross-sectional width and contour of alveolar bone can be found out using conventional or computed tomography. ${ }^{3-6}$ But exposure to ionizing radiation, universal non-availability, and high cost limits their use in day to day practice. Whereas clinical techniques provide information about bone width and contour at relative ease without the abovementioned drawbacks. This clinical technique is called a bone probing technique of ridge mapping or bone mapping., ${ }^{7,8}$ The two techniques of bone mapping are (a) direct, (b) indirect technique. The direct technique uses a specially designed bone caliper and indirect techniques employ specifically designed pre-fabricated guides. ${ }^{9,10}$ Even though both direct and indirect techniques are used commonly, the validity of the indirect technique has not been confirmed. Studies have been done to compare the efficacy of one radiographic technique over another. ${ }^{11-14}$ There are no studies in the literature to confirm these techniques utilizing different materials for the guides. Hence, this study was taken up to compare the direct and indirect techniques of ridge mapping using two different materials, during treatment planning for dental implants.

\begin{abstract}
1Department of Prosthodontics, Sriramakrishna Dental College and Hospital, Coimbatore, Tamil Nadu, India

${ }^{2}$ Department of Prosthodontics, AB Shetty Memorial Institute of Dental Sciences, (A Constituent College of Nitte deemed to be University), Mangaluru, Karnataka, India
\end{abstract}

Corresponding Author: S Sriram Balaji, Department of Prosthodontics, Sriramakrishna Dental College and Hospital, Coimbatore, Tamil Nadu, India, Phone: +918015382800, e-mail: drssrirambalaji86@gmail.com

How to cite this article: Balaji SS, Bhat V. A Study to Determine the Accuracy of Various Clinical Techniques of Ridge Mapping before Implant Fixture Placement. J Contemp Dent Pract 2019;20(4):499-503.

Source of support: Nil

Conflict of interest: None

\section{Materials AND METHOdS}

After obtaining written, Informed consent to participate, the study was conducted on a group of 10 patients who reported to the Department of Prosthodontics, AB Shetty Memorial Institute of Dental Sciences, Nitte (Deemed to be University), Deralakatte, Mangaluru, Karnataka, India. Individuals of age group between 20-40 years and edentulous areas in the mandible with at least two teeth missing adjacent to each other were included in the study.

Two dentulous trays of the same size were selected for impression making, and they were modified with tissue stops using baseplate wax. This would ensure standardizing the pressure that is applied during the procedure of impression making. Two sets of impressions with opposing arch were recorded for each patient using irreversible hydrocolloid (Neocolloid, Zhermack Dental). Impressions were poured using type IV dental stone (Kalrock, Kalabhai)and the height of the casts was standardized $(25 \mathrm{~mm})$ by measuring the distance between cusp tip of adjacent teeth to the base of the sulcus using a divider. The base for the casts was

(C) The Author(s). 2019 Open Access This article is distributed under the terms of the Creative Commons Attribution 4.0 International License (https://creativecommons. org/licenses/by-nc/4.0/), which permits unrestricted use, distribution, and non-commercial reproduction in any medium, provided you give appropriate credit to the original author(s) and the source, provide a link to the Creative Commons license, and indicate if changes were made. The Creative Commons Public Domain Dedication waiver (http://creativecommons.org/publicdomain/zero/1.0/) applies to the data made available in this article, unless otherwise stated. 
fabricated taking care to maintain occlusal plane parallel to the floor. Casts were identified as $\mathrm{A}$ (acrylic resin guide) and $\mathrm{T}$ (thermoplastic resin guide) on their bases.

The face-bow transfer was done and casts were mounted on a semi-adjustable articulator. Diagnostic wax-up was done, and the center of each tooth was identified as a site for future implant placement. Through the center of each artificial tooth, a hole was drilled corresponding to its central fossa to contact the crest of the ridge below. This represents the future sites (points $C_{1}$ and $C_{2}$ ) for implant placement (Fig. 1). Guides were fabricated on cast $A$ and $T$ using acrylic and thermoplastic resin, respectively.

\section{Fabrication of Acrylic Resin Guide}

A groove was made on the buccal and lingual side of the cast in the sulcus using no 8 round bur. This groove will act as a positive stop for the putty index when the acrylic is being flown into space. A modeling wax of $1 \mathrm{~mm}$ thickness was adapted on to the ridge to extend up to the groove on both sides. Next, an index was made of silicone putty material (Speed ex coltene-whaledent) and the adapted wax was removed. Separating medium was applied on the edentulous ridge, two adjacent teeth and inner surface of the index. Auto polymerizing acrylic resin (DPI PR Cold cure) was mixed and was placed on the edentulous site in the dough stage. Over this, the prepared silicone index was placed ensuring proper seating on the prepared groove. This was done to avoid

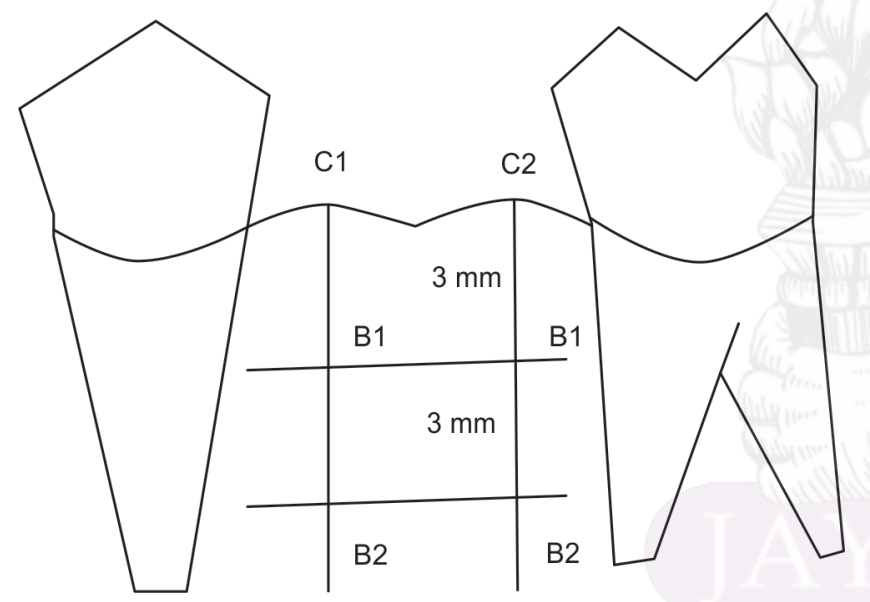

Fig. 1: Implant site identification

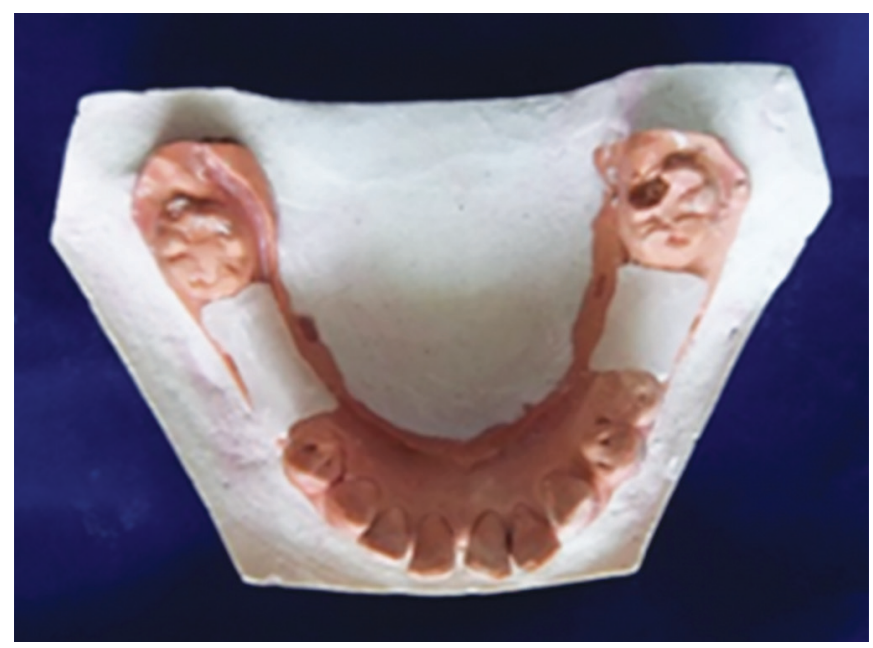

Fig. 2: Acrylic guide applying undue pressure on the index. The auto-polymerizing resin was allowed to polymerize completely before it was removed from the cast and excess material was trimmed off. The acrylic guide was trimmed, polished and the fit was verified on the cast (Fig. 2).

\section{Fabrication of Thermoplastic Resin Guide}

A $1 \mathrm{~mm}$ thick thermoplastic resin sheet was selected and was adapted over the cast using vacuum forming machine (Raintree Essix-vacuum forming machine, Dentsply) Excess resin sheet beyond the groove was cut and the fit was verified on the cast. The cut sides were smoothened and polished (Fig. 3).

\section{Preparation for Ridge Mapping}

Each guide was placed separately on the cast and the site of implant placement was marked as $\mathrm{C} 1$ and $\mathrm{C2}$, on the crest of the ridge. From point C1, $3 \mathrm{~mm}$ distance buccally and lingually was marked as B1 and L1, respectively (First Level), and from point C2, $6 \mathrm{~mm}$ distance buccally and lingually was marked as $B 2$ and L2 respectively (second level). The same procedure was repeated for the second implant site and identified as $C 2$. These points were transferred to the guide and holes were prepared on the points B1, B2, L1, L2 using no 6 round bur.

The guides were stored in $2 \%$ Glutaraldehyde for 10 minutes before ridge mapping.

Then the cast was sectioned at points $\mathrm{C} 1$ and $\mathrm{C} 2$ starting from the crest, along with the two points marked buccally and lingually.

\section{Ridge Mapping Procedure}

The procedure of ridge mapping was explained to the patient prior to initiating. Topical local anesthesia was sprayed on the selected site and the disinfected thermoplastic resin guide was placed on the edentulous area. Once satisfactory anesthesia was achieved, a sterile endodontic file no. 15 with stopper was placed through the hole corresponding to $\mathrm{C} 1$. It was pushed through the mucosa until it contacted the bone. The stopper of the file was adjusted to make contact with the guide (Fig. 4). Then the file was pulled out and was held against the sectioned cast corresponding to $\mathrm{C} 1$ point. The stopper was held in contact the surface of the cast at that point and the point where the tip of the file contacts along the cut surface of the cast is marked using a lead pencil. The above procedure was carried out for all the points and on both the sites of implant placement.

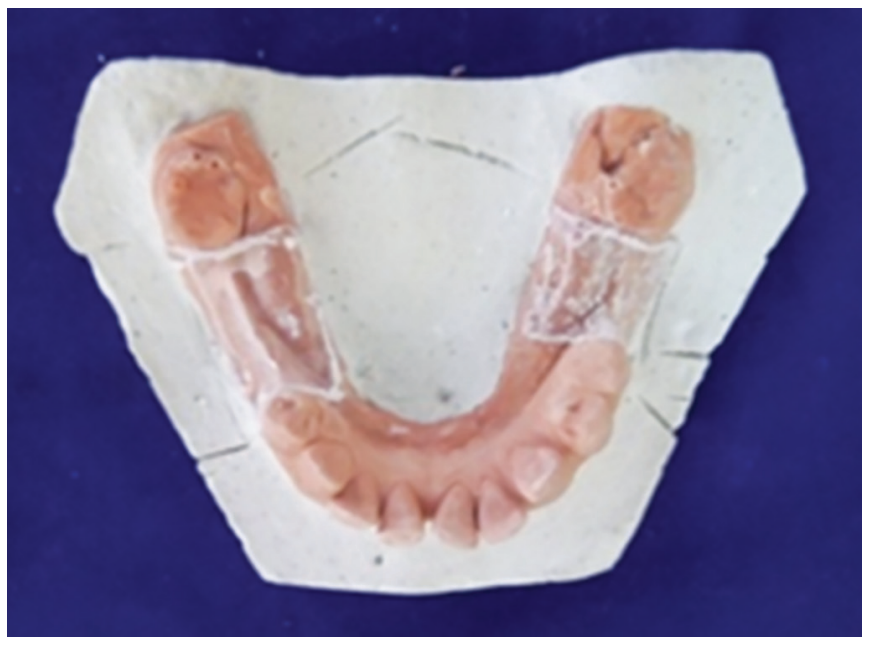

Fig. 3: Thermoplastic resin guide 


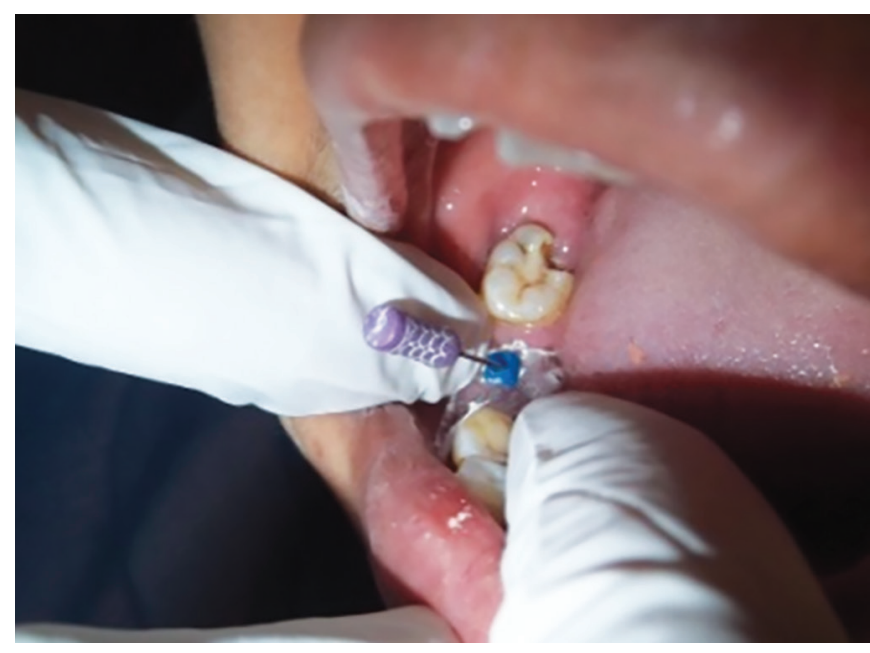

Fig. 4: Using endodontic file

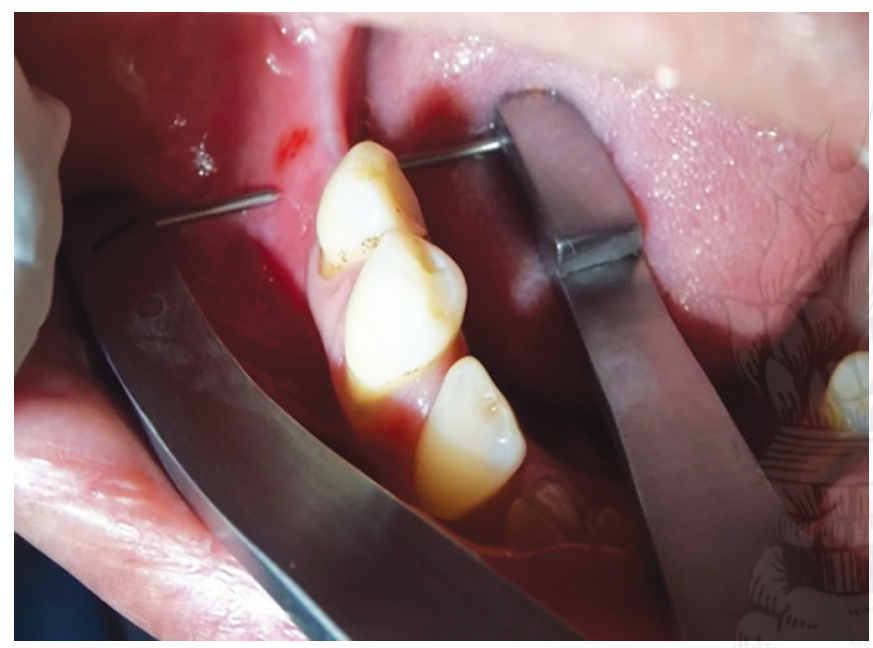

Fig. 6: Direct technique of ridge mapping

Then the thermoplastic resin guide was replaced by acrylic resin guide, and the same procedure was carried out.

After the above, all the five points on each side were connected using lead pencil on the cut surface of the cast. Using a divider and scale the distance between B1, L1, and B2, L2 was measured for each guide and each site. This represents the bone width available for implants at the first level and second level at each implant site (C1 and C2) (Fig. 5).

\section{Direct Technique}

Measurements were recorded directly from the patient using bone caliper in the predetermined points obtained through the indirect technique. These points were identified as bleeding spots created during the indirect technique of ridge mapping (Fig. 6).

Once all the measurements were made, the area was cleaned and wiped off blood using sterile gauze. Necessary instructions were given to the patient before dismissing. The values obtained were then tabulated.

\section{Results}

The values obtained were tabulated and statistically analyzed using one way ANOVA test for individual comparisons and multiple

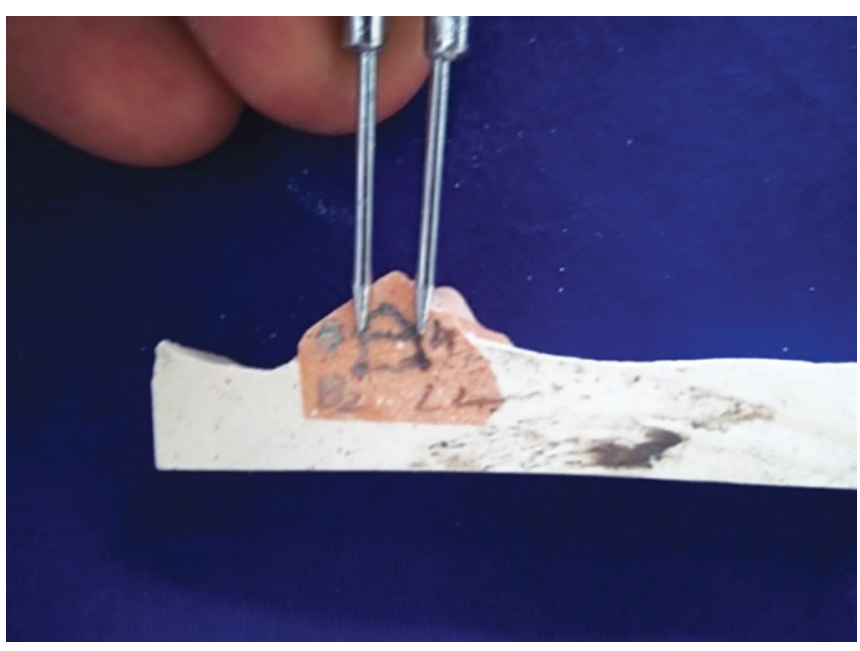

Fig. 5: Measuring the width

comparisons among the groups were performed using Tukey's HSD test.

Comparison between B1L1 and B2L2 values between Direct Technique and Indirect Technique Guide T and Guide A using one way ANOVA test revealed there was no statistically significant difference observed at B1L1and B2L2 levels Using direct technique and indirect technique using guide $T$ and guide $A$ (Table 1).

When multiple comparisons between B1L1 and B2L2 levels using Tukey HSD test was done.

It showed there was no statistically significant difference between B1L1 and B2L2 using direct technique and indirect technique using guide $T$ and guide $A$ (Table 2).

Results show that the mean value of B1L1 indirect technique and indirect technique using guide and guide $A$ is 3.38 and the standard deviation is 0.495 . There was no statistically significant difference observed at B1L1 levels using the direct and indirect technique. Also, the mean value of B2L2 indirect technique and indirect technique using guide $T$ and guide $A$ is 6.42 and the standard deviation is 0.776 . Hence, there was no statistically significant difference observed at B2L2 levels using direct technique and indirect technique using guide $T$ and guide $A$.

\section{Discussion}

The similar values might be due to the astute care taken for standardization in the study.

Standardization was given the prime importance in the study since the values expected from the study is only of a few millimeters. So it can be understood that both direct and indirect techniques are satisfactory to measure bone width. Similar results were also obtained when multiple comparisons were done using Tukey's HSD test. Both the intergroup comparison and intragroup comparison were done. All the comparisons revealed the equality of both direct and indirect technique in the assessment of available bone width. This shows that the indirect technique is equally effective as a direct technique. In the absence of a bone caliper, the indirect technique can be implemented.

If an indirect technique is utilized, the guide can be fabricated using either acrylic resin or thermoplastic resin depending on the availability in the dental office. Studies have concluded that CBCT was less consistent when compared to direct caliper measurements and $C B C T$ did not provide any additional significant diagnostic information. ${ }^{15}$ Also, recent studies indicate that ridge mapping is 
Ridge Mapping for Dental Implants

Table 1: Comparison between b1/1 and b2/2 values between direct technique and indirect technique guide $t$ and guide a using one way anova test

\begin{tabular}{llllllll}
\hline & $N$ & Mean & Std. deviation & Mean Square & $F$ & Sig. \\
\hline B1 L1 & Indirect t & 8 & 3.38 & 0.518 & 0 & 0.518 & \\
& Indirect a & 8 & 3.38 & 3.38 & 0.518 & & \\
& Direct technique & 8 & 3.38 & 0.495 & & 0.462 & \\
\hline B2L2 & Total & Indirect t & 24 & 6.38 & 0.744 & 0.292 & \\
& Indirect a & 8 & 6.25 & 0.707 & & \\
& Direct technique & 8 & 6.63 & 0.916 & & \\
\hline
\end{tabular}

Table 2: Multiple comparisons between B1L1 and B2L2 levels using Tukey HSD test

\begin{tabular}{|c|c|c|c|c|c|}
\hline \multicolumn{6}{|c|}{ Multiple comparisons } \\
\hline \multicolumn{6}{|c|}{ TukeyHSD } \\
\hline Dependent variable & (I) technique & (J) Technique & Mean difference (I-J) & Std. error & Sig. \\
\hline \multirow[t]{3}{*}{ B1 L1 } & Indirect t & Indirect A & 0.000 & 0.259 & 1.000 \\
\hline & & Direct technique & 0.000 & 0.259 & 1.000 \\
\hline & Indirect a & Direct technique & 0.000 & 0.259 & 1.000 \\
\hline \multirow[t]{3}{*}{ B2 L2 } & Indirect t & Indirect A & 0.125 & 0.397 & 0.947 \\
\hline & & Direct technique & -0.250 & 0.397 & 0.806 \\
\hline & Indirect a & Direct technique & -0.375 & 0.397 & .619 \\
\hline
\end{tabular}

an accurate indicator of available bone width when compared with other radiographic methods. ${ }^{16-21}$

From the present study, it can be concluded that ridge mapping is a significant diagnostic tool for the preoperative assessment of available bone width which can be performed chairside, economical and without any radiation exposure. Use of bone caliper or guides prepared using thermoplastic resin or auto polymerizing acrylic resin yields the same clinical results. This is the first study conducted of its kind comparing the various techniques of ridge mapping, and it may serve as a protocol for future studies to follow in this field. Indirect technique is as effective as compared to direct technique. In the absence of a bone caliper, the indirect technique can be implemented. If the indirect technique is utilized, the guide can be fabricated using either acrylic resin or thermoplastic resin depending on the availability in the dental office.

\section{CONCLUSION}

From the present study, it can be concluded that:

- Both direct and indirect techniques can be used with equal reliability to determine the width of the available bone before dental implant placement.

- Both, thermoplastic and autopolymerising acrylic resins yield similar results when used for determination of bone width during indirect ridge mapping procedure.

\section{Clinical significance}

Clinical techniques of ridge mapping are handy and can be carried out chairside with ease and less cost and no radiation exposure. indirect techniques of ridge mapping provide adequate and reliable data regarding bone width just like direct technique. In the absence of a bone mapping caliper, this technique can be used as a diagnostic procedure before implant placement. And during the indirect technique, any material can be utilized with equal efficacy for the fabrication of the guides.

\section{References}

1. Sümnig W. Determining the alveolar ridge width in planning treatment with endosseous implants. Stomatologie der DDR 1990: 40(3): 120-121.

2. Eufinger $H$, König $S$, Eufinger $A$. The role of alveolar ridge width in dental implantology.Clinical Oral Investigations 1998;1(4):169-177.

3. Williams MY, Mealey BL, Hallmon WW. The role of computerized tomography in dental implantology.Int J Oral Maxillofac Implants 1992 Fall;7(3):373-380.

4. Ekestubbe A, Gröndahl K, Gröndahl HG. The use of tomography for dental implant planning.Dentomaxillofacial Radiology .1997; 2:,206-213.

5. Schwarz MS, Rothman SL, Chafetz N, et al. Computed tomography in dental implantation surgery.Dent Clin North Am. 1989 Oct;33(4):555597.

6. Weinberg LA. CT scan data as radiologic base for optimum dental implant orientation. J Prosthet Dent 1993;69(4):381-385.

7. Wilson DJ. Ridge mapping for determination of alveolar ridge width. Int J Oral Maxillofac Implants. 1989 Spring;4(1):41-43.

8. Ten Bruggenkate CM, de Rijcke TB, Kraaijenhagen HA, Oosterbeek HS. Ridge mapping. Implant Dent 1994 Fall;3(3):179-182.

9. Windhom RJ. Fabrication and use of a simple implant placement guide. Journal of Prosthetic Dentistry 2002;92(2):196-199.

10. Stuempell LJ. Cast based guided implant placement. A novel technique. Journal of Prosthetic Dentistry 2008;100(1):61-69.

11. Zosky JGIn-office linear tomography: a new technology for definitive preplanning of endosteal implant sites. Int J Dent Symp 1995;3(1):26-29.

12. Traxler $M$, Ulm C, Solar $P$, et al. Sonographic measurement versus mapping for determination of alveolar ridge width. J Prosthet Dent 1992; 67(3): 358-361.

13. Lam E, Ruprechet A, Yang L. Comparision of 2 dimensionally orthoradially reformatted computed tomography and panaromic radiography for dental implant treatment planning. J Prosthet Dent. 1995;74 (3):42-46.

14. Tal $\mathrm{H}$, Moses $\mathrm{O}$. A comparison of panoramic radiography with computed tomography in the planning of implant surgery. Dentomaxillofacial Radiology.1991;2:40-42.

15. Chen LC, Lundgren T, Hallström $\mathrm{H}$, et al. Comparison of Different Methods of Assessing Alveolar Ridge Dimensions Prior to Dental Implant Placement.Journal of Periodontology 2008;79(3):401-405. 
16. Castro-Ruiz CT, Noriega J, Guerrero ME. Validity of ridge mapping and computed tomography in dental implant therapy. Journal of Indian Society of Periodontology 2015;19(3):290-293.

17. Castro-RuizCT, Noriega J, Guerrero ME. Technique to assess the alveolar bone width for immediate implant placement in fresh extraction socket. Indian journal of dental research. 2013;24(6):784-786.

18. Chugh A, Bhisnoi P, Kalra D, et al. Comparative evaluation of three different methods for evaluating alveolar ridge dimension prior to implant placement: An in vivo study. Journal of dental implants. 2013;3(2)
19. Luk LC, Pow EH, Li TK, et al. Comparision of ridge mapping and cone beam computed tomography forplanning dental implant therapy. Int J Oral Maxillofac Implants 2011;26(1):70-74.

20. Behnia $\mathrm{H}$, Haidi $\mathrm{A}$. An assessment of the accuracy of ridge mapping versus ct scan in determination of alveolar ridge width. J Dent Sch 2006;24(3):291-297.

21. Dave BH, Sutaria S, Mehta S, et al. A comparative study of three different methods for evaluating width of alveolar ridge prior to implant placement: An in vivo study. Int J Oral Care Res 2017;5(1): 53-60. 